\title{
Nucleation Kinetics of L-Arginine, L-Lysine and L-Alanine Doped Potassium Dihydrogen Phosphate Crystals
}

\author{
K. D. Parikh ${ }^{*}$, B. B. Parekh², D. J. Dave ${ }^{3}$, M. J. Joshi ${ }^{2}$ \\ ${ }^{1}$ M. P. Shah Arts and Science College, Surendranagar, India; ${ }^{2}$ Pandit Deendayal Petroleum University, Gandhinagar, India; \\ ${ }^{3}$ Department of Physics, Saurashtra University, Rajkot, India. \\ Email: *ketandparikh@yahoo.co.in, mshilp24@rediffmail.com
}

Received February $13^{\text {th }}, 2013$; revised March $14^{\text {th }}, 2013$; accepted March $22^{\text {nd }}, 2013$

Copyright (C) 2013 K. D. Parikh et al. This is an open access article distributed under the Creative Commons Attribution License, which permits unrestricted use, distribution, and reproduction in any medium, provided the original work is properly cited.

\begin{abstract}
The solubility, induction period and nucleation parameters of pure and amino acids like L-arginine, L-lysine and L-alanine doped potassium dihydrogen phosphate (KDP) crystals have been determined. Solubility study of pure and amino acids doped KDP crystals were carried out for different temperatures. The induction period was measured at different supersaturation level. The nucleation parameters like interfacial tension, radius of critical nucleus and energy of formation were calculated based on the classical theory of nucleation. Values of different parameters were found to be larger for amino acid doped crystals than pure KDP crystal.
\end{abstract}

Keywords: Nonlinear Optical Materials; Solubility; Induction Period; Nucleation

\section{Introduction}

Recently, potassium dihydrogen phosphate (KDP) crystals have created considerable interest because of its Piezo-electric, electro-optic, nonlinear optical properties and its extensive application in X-ray monochromators $[1,2]$. Amino acid family crystals also exhibit excellent electro-optic and nonlinear optical properties. Review of literature shows that some of the technologically important crystals doped with amino acids for improved material characteristics like nonlinear optical and ferroelectric properties are observes. Enhancement of second harmonic generation (SHG) efficiency has also been reported by doping of amino acids like L-arginine [3], Llysine [4] and L-alanine [5] into KDP crystals. The characteristics of pure, L-arginine, L-lysine and L-alanine doped KDP crystals viz. FT-IR, powder XRD, SHG, UV-vis, TGA and dielectric study have already been reported in our earlier papers [3-5]. Present work is aimed to grow KDP crystals doping with L-arginine, L-lysine and L-alanine $(0.3$ weight $\%$ to 0.5 weight $\%$ ) to study their effects on the nucleation parameters.

\section{Experimental Procedure}

\subsection{Doping Process}

The doping of amino acids (L-arginine, L-lysine and L-

${ }^{*}$ Corresponding author. alanine) into KDP (AR grade) were carried out by adding $0.3,0.4$ and 0.5 weight percentage powder form of amino acid into 1 molar $100 \mathrm{ml}$ solution of KDP in double distilled water. The mixtures were thoroughly stirred for 1 hour for homogenization.

\subsection{Solubility Studies}

It is desirable to study the solubility of the material in a suitable solvent before proceeding for the crystal growth. In the present work, solubility of pure and different amino acids doped KDP crystals was determined in water for different temperatures. The solutions of pure and doped KDP crystals were kept at a constant temperature bath of HMG INDIA having an accuracy of $\pm 0.1^{\circ} \mathrm{C}$ with constant stirring. $100 \mathrm{ml}$ solution of each sample was taken to measure the dissolved solute. For this, double distilled water was used as a solvent throughout the experiment. Same process was repeated for different temperature. Different weight percentages, i.e. $0.3 \mathrm{wt} \%, 0.4$ $\mathrm{wt} \%$ and $0.5 \mathrm{wt} \%$ amino acids (L-arginine, L-lysine and L-alanine) were added and the solubility was measured.

\subsection{Determination of Induction Period}

The time required achieving supersaturation or supercooling and the appearance of crystal nucleus in a supersaturated system is known as the induction period. De- 
pending upon the solubility of the material, one can choose the appropriate technique available in order to determine induction period. For example, if materials have low solubility, the conductivity and turbidity methods are suitable. On the other hand, for materials with high solubility, the dilatometer and direct vision methods are used. This has been discussed extensively by several authors [6-8].

In the present study, the experimental technique used to measure induction period is the modification one used by Mullin, Joshi and Antony [9,10]. The supersaturated solutions of both the pure and amino acids doped KDP crystal were prepared at $35^{\circ} \mathrm{C}$ in accordance with the available solubility data of KDP crystal. In order to ensure that any unwanted metallic or non metallic impurity do not effect in the nucleation process, an AR grade KDP powder and double distilled water were used. For this, aqueous solutions of various supersaturated concentrations were prepared. The volume of solution taken for each experiment was $100 \mathrm{ml}$. The mixture was then heated a few degree above the saturation temperature $\left(35^{\circ} \mathrm{C}\right)$ with stirring to achieve homogeneous concentration. The solution was cooled to the required degree of supersaturation. The supersaturated solution of equal volume was then kept in a specially design glass vessel as shown in Figure 1. The glass vessel was $20 \mathrm{~cm}$ in length, with $1.7 \mathrm{~cm}$ and $0.4 \mathrm{~cm}$ top and neck diameter respecttively. This is noticed worthy that a constant temperature bath was used for this purpose.

Once the nucleation occurred, it grew quickly and a bright sparkling crystal was seen at the bottom of the vessel. The time of observation of the sparkling crystal in the vessel from the time at which the solution reaches the saturation temperature gives the induction period of nucleation. These experiments were performed at selected degrees of supersaturation $\left(\mathrm{C} / \mathrm{C}^{*}\right)$, viz. $1.2,1.3,1.4$ and 1.5 , where $\mathrm{C}$ is the concentration of solute in supersaturated solution at the saturated temperature and $\mathrm{C}^{*}$ is the saturated concentration. For each supersaturation level average value of three trials were recorded to ensure the accuracy. The experiments were reported for $0.3 \mathrm{wt} . \%$ to 0.5 wt. \% doping of L-arginine, L-lysine and L-alanine

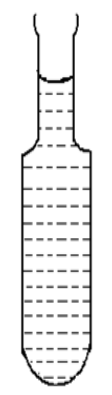

Figure 1. Specially designed container used for measurement of induction period. added in the KDP solutions.

\section{Results and Discussion}

The classical homogeneous nucleation theory has been successfully verified for different crystal systems. Paul and Joshi [11] studied the effect of supersaturation on the induction period of KDP crystal. They calculated the surface energy of $546 \mathrm{erg} \mathrm{cm}-2$ at the phase boundary which separates the growing crystals from the solution. Shanmugham et al. [12] studied the nucleation of KDP crystal. The nucleation rates were studied for supersaturated solution of potassium dihydrogen orthophosphate with and without the addition of soluble impurities in the temperature range from $20^{\circ} \mathrm{C}$ to $40^{\circ} \mathrm{C}$. They also discussed the effects of temperature, supersaturation and impurity content more extensively. The interfacial tension, energy of formation and critical radius of nuclei were calculated on basis of classical nucleation theory. It was found that the selected soluble impurities such as $\mathrm{K}_{2} \mathrm{CO}_{3}, \mathrm{~K}_{2} \mathrm{PO}_{4}, \mathrm{~K}_{2} \mathrm{C}_{2} \mathrm{O}_{4}, \mathrm{Na}_{2} \mathrm{~B}_{4} \mathrm{O}_{7}$ and $\mathrm{K}_{2} \mathrm{CrO}_{4}$ were responsible to enhance the nucleation rate of KDP crystals. More on, Shanmugham et al. [13] also reported nonsteady state nucleation process in KDP solution in the presence of XO4 impurities. Based on the probabilistic approach compared to the nucleation process, the steady state nucleation rate was inversely related to the induction period of the non-steady state time lag, the time of formation of first nucleation. During this study, the calculation of different nucleation parameters for $\mathrm{CrO}_{4}^{2-}$, $\mathrm{SO}_{4}^{2-}, \mathrm{IO}_{4}^{2-}, \mathrm{MnO}_{4}^{1-}$ and $\mathrm{ClO}_{4}^{1-}$ impurities were also calculated.

In 1999, the nucleation studies of KDP doped by $\mathrm{KBr}$ and $\mathrm{K}_{2} \mathrm{Cr}_{2} \mathrm{O}_{7}$ were presented by Mahadevan et al. [14]. They measured induction period by direct vision method and calculated different parameters by classical theory of homogeneous crystal nucleation. It was reported that the critical nucleation parameters increases with a corresponding rise in doping concentration for both the dopants. Dhanaraj et al. performed KDP nucleation crystals study by adding L-arginine mono hydrochloride (LAHCl) in 2008 [15]. For this, the dopant concentration was varied from 1 to $10 \mathrm{~mol} \%$. It was found that the meta-stable zone width of KDP was enhanced with the addition of LAHCl. The effect of stirring solution on induction period for precipitation of KDP was studied by Barata and Serrano [16]. They measured induction period as a function of super saturation in the agitation range from 50 to $500 \mathrm{rpm}$ by visual method. The induction periods were constant between 50 to $400 \mathrm{rpm}$, however, later; it was decreased due to decline in the Kolmogoroff turbulence micro scale.

\subsection{Solubility Curves}

The solubility curves for pure KDP and doped with 0.3 


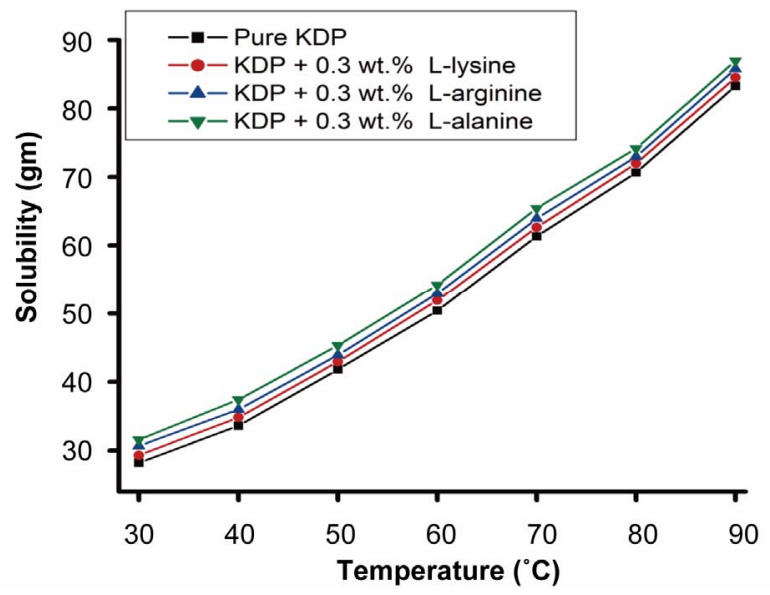

Figure 2. Solubility curves for pure and $0.3 \mathrm{wt} \%$ L-arginine, L-lysine, L-alanine doped KDP crystals.

wt $\%$ L-arginine, $0.3 \mathrm{wt}^{\mathrm{O}} \%$ L-lysine and $0.3 \mathrm{wt} \% \mathrm{~L}-$ alanine are shown in Figure 2. It is observed that the solubility of pure and amino acids added KDP increases with an increase in temperature. However, the solubility of doped KDP increases marginal with respect to pure KDP. The solubility of different samples of solution was found in the following order; Pure KDP $<$ (KDP + L-lysine $)<(\mathrm{KDP}+$ L-arginine $)<(\mathrm{KDP}+$ L-alanine $)$. The variation in the solubility may be due to the difference of solubility of different amino acids.

\subsection{Nucleationkinetics}

Non-steady and steady state nucleation processes are related by the induction period. Through certain processes, the induction period is related to the size and complexity of the critical nucleus which can be affected by external influences. This induction period has been frequently used as a measure of the nucleation rate. The induction period is devoted to nucleus formation and is inversely proportional to the steady state nucleation rate $\tau \propto \mathrm{J}^{-1}$.

$$
\ln \tau=\ln B+16 \pi \gamma^{3} V^{2} N / 3 R^{3} T^{3}(\ln S)^{2}
$$

where, $\tau$ is the induction period of the solution at temperature $T, V$ is the molar volume of the crystal, $\gamma$ is the interfacial tension, $S$ is the supersaturation ratio $(\mathrm{S}=$ $\left.\mathrm{C} / \mathrm{C}^{*}\right), N$ is the Avogadro's number and $R$ is the gas constant.

Equation (1) suggests that the plot of $\ln \tau$ against $1 /(\ln S)^{2}$ is straight line. It can be drawn with slope of

$$
m=16 \pi \gamma^{3} V^{2} N / 3 R^{3} T^{3}
$$

The interfacial tension of the solid relative to its solution can be calculated as;

$$
\gamma=R T\left[3 m / 16 \pi V^{2} N\right]^{1 / 3}
$$

The energy of formation of a critical nucleus can be calculated from the experimental using following relation.

$$
\Delta G=m R T /(\ln S)^{2}
$$

The radius of the nucleus in equilibrium with its solution can be computed as;

$$
r=2 \gamma V / R T(\ln S)
$$

The effect of supersaturation on induction period experiments were conducted for various level of supersaturation $(\mathrm{S}=1.2$ to 1.5$)$ at $35^{\circ} \mathrm{C}$ temperature. The data is presented in Table 1, which shows that the induction period decreases with increase in supersaturation level. Different values of few critical parameters such as the interfacial tension $(\gamma)$, the energy of formation $(\Delta G)$ and the radius of critical nucleus (r) are calculated using Equations (3), (4) and (5) respectively. Equation (1) suggests a linear nature for plot of $\ln \tau$ versus $1 /(\ln S)^{2}$ can be drawnfor pure, L-arginine, L-lysine and L-alanine doped KDP crystals as illustrated in Figures 3-5 respectively. However the plotted data as depicted in Figures 3-5 is not linear as observed by Shanmugham et al. [12].

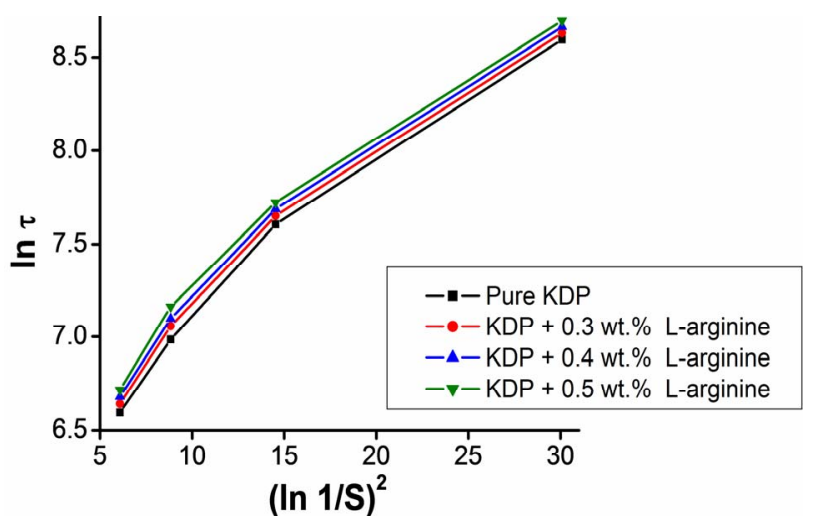

Figure 3. Plots of $\ln \tau$ versus $1 /(\operatorname{lnS})^{2}$ for pure and L-arginine, doped KDP crystals.

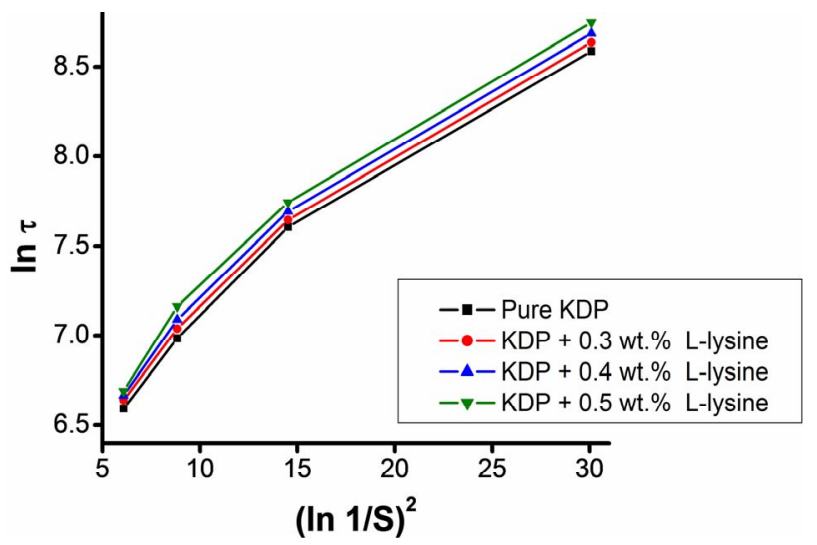

Figure 4. Plots of $\ln \tau$ versus $1 /(\operatorname{lnS})^{2}$ for pure and, L-lysine doped KDP crystals. 


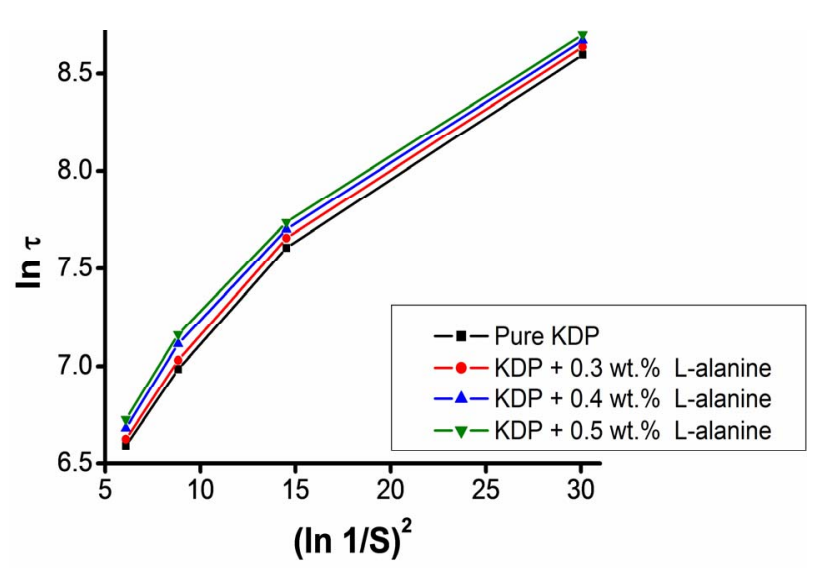

Figure 5. Plots of $\ln \tau$ versus $1 /(\ln S)^{2}$ for pure and L-alanine doped KDP crystals.

Whereas, the linear nature observed above 1.3 supersaturation was used to calculate various nucleation parame ters [12]. The similar results were obtained by Shanmugham $[12,13]$. Moreover, the condensation of water nuclei from vapour in the presence of soluble salts like ammonium sulphate and sodium chloride exhibited similar results [17]. The values of different nucleation parameters are listed in Table 1. This clearly indicates that the radius of critical nucleus decreases as the supersaturation increase. Contrary to this, an increase in energy of formation was observed with corresponding rise in the supersaturation. Similarly, doping of amino acid also results an increases in the interfacial tension. The change in the nature of various parameters due to increase in supersaturation is believed due to change in the solubility of various amino acids and KDP.

\section{Conclusion}

The solubility of KDP crystals increases with an increase in temperature. Compared to pure KPD crystal, the solubility of amino acids doped KPD crystal were high at a given temperature. With an increased in the doping level of amino acids, a marginal increase in the induction period for particular supersaturation was observed. This concludes that the doping of amino acids has an ultimate effect on the nucleation process. The values of interfacial tension, formation energy of critical nucleus and radius of critical nucleus were calculated at various supersaturation levels for both pure and doped KDP crystals using classical nucleation theory. It was found that the energy of formation increases and the radius of critical nucleus decreased with a corresponding increase in the supersaturation level. Finally, the values of different nucleation parameters were calculated. We found that these parameters were comparatively larger than amino acids doped KDP crystals.
Table 1. Nucleation parameters of pure, L-arginine, L-lysine and L-alanine doped KDP crystals.

\begin{tabular}{|c|c|c|c|c|c|}
\hline Sample & $\begin{array}{c}\text { Super- } \\
\text { saturation }\end{array}$ & $\begin{array}{l}\text { Induction } \\
\text { period (s) }\end{array}$ & $\begin{array}{l}\text { Energy of } \\
\text { formation } \\
\left(\mathrm{J} \cdot \mathrm{mol}^{-1}\right)\end{array}$ & $\begin{array}{c}\text { Radius of } \\
\text { Critical } \\
\text { nucleus } \\
(\mathbf{n m})\end{array}$ & $\begin{array}{c}\text { Interfacial } \\
\text { Tension } \\
\left(\mathbf{m J} \cdot \mathbf{m}^{-2}\right)\end{array}$ \\
\hline \multirow{4}{*}{ Pure KDP } & 1.2 & 5415 & 936.5 & 4.30 & \multirow{4}{*}{16.87} \\
\hline & 1.3 & 3065 & 1939.4 & 2.99 & \\
\hline & 1.4 & 1635 & 3189.7 & 2.33 & \\
\hline & 1.5 & 680 & 4631.9 & 1.93 & \\
\hline \multirow{4}{*}{$\begin{array}{c}\mathrm{KDP}+0.3 \\
\text { wt } \% \\
\text { L-arginine }\end{array}$} & 1.2 & 5590 & 1058.0 & 4.46 & \multirow{4}{*}{17.52} \\
\hline & 1.3 & 3165 & 2190.8 & 3.10 & \\
\hline & 1.4 & 1695 & 3603.3 & 2.42 & \\
\hline & 1.5 & 705 & 5232.5 & 2.01 & \\
\hline \multirow{4}{*}{$\begin{array}{c}\mathrm{KDP}+0.4 \\
\text { wt } \% \\
\text { L-arginine }\end{array}$} & 1.2 & 5590 & 1109.0 & 4.63 & \multirow{4}{*}{18.16} \\
\hline & 1.3 & 3185 & 2296.4 & 3.22 & \\
\hline & 1.4 & 1715 & 3776.9 & 2.51 & \\
\hline & 1.5 & 730 & 5484.6 & 2.08 & \\
\hline \multirow{4}{*}{$\begin{array}{c}\mathrm{KDP}+0.5 \\
\mathrm{wt} \% \\
\mathrm{~L}-\text { arginine }\end{array}$} & 1.2 & 5630 & 1151.4 & 4.80 & \multirow{4}{*}{18.83} \\
\hline & 1.3 & 3225 & 2384.4 & 3.33 & \\
\hline & 1.4 & 1715 & 3921.6 & 2.60 & \\
\hline & 1.5 & 755 & 5694.8 & 2.16 & \\
\hline \multirow{4}{*}{$\begin{array}{c}\text { KDP }+0.3 \\
\text { wt.\% } \\
\text { L-lysine }\end{array}$} & 1.2 & 5505 & 1045.2 & 4.39 & \multirow{3}{*}{17.22} \\
\hline & 1.3 & 3135 & 2164.4 & 3.05 & \\
\hline & 1.4 & 1675 & 3559.9 & 2.38 & \\
\hline & 1.5 & 685 & 5169.4 & 1.97 & \multirow{5}{*}{17.66} \\
\hline \multirow{4}{*}{$\begin{array}{c}\mathrm{KDP}+0.4 \\
\mathrm{wt} \% \mathrm{~L}-\text {-lysine }\end{array}$} & 1.2 & 5535 & 1086.0 & 4.50 & \\
\hline & 1.3 & 3175 & 2248.9 & 3.13 & \\
\hline & 1.4 & 1720 & 3698.8 & 2.44 & \\
\hline & 1.5 & 715 & 5400.6 & 2.02 & \\
\hline \multirow{4}{*}{$\begin{array}{c}\mathrm{KDP}+0.5 \\
\mathrm{wt} \% \mathrm{~L}-\text { lysine }\end{array}$} & 1.2 & 5545 & 1121.7 & 4.57 & \multirow{4}{*}{17.92} \\
\hline & 1.3 & 3205 & 2322.8 & 3.17 & \\
\hline & 1.4 & 1735 & 3820.3 & 2.47 & \\
\hline & 1.5 & 730 & 5547.7 & 2.05 & \\
\hline \multirow{4}{*}{$\begin{array}{c}\mathrm{KDP}+0.3 \\
\text { wt } \% \\
\text { L-alanine }\end{array}$} & 1.2 & 5535 & 1052.0 & 4.47 & \multirow{4}{*}{17.56} \\
\hline & 1.3 & 3150 & 2178.5 & 3.11 & \\
\hline & 1.4 & 1725 & 3583.0 & 2.42 & \\
\hline & 1.5 & 710 & 5203.0 & 2.01 & \\
\hline \multirow{4}{*}{$\begin{array}{c}\mathrm{KDP}+0.4 \\
\text { wt } \% \\
\text { L-alanine }\end{array}$} & 1.2 & 5585 & 1126.0 & 4.63 & \multirow{4}{*}{18.16} \\
\hline & 1.3 & 3185 & 2331.6 & 3.22 & \\
\hline & 1.4 & 1740 & 3834.8 & 2.51 & \\
\hline & 1.5 & 735 & 5568.7 & 2.08 & \\
\hline \multirow{4}{*}{$\begin{array}{c}\mathrm{KDP}+0.5 \\
\text { wt } \% \\
\text { L-alanine }\end{array}$} & 1.2 & 5610 & 1143.8 & 4.76 & \multirow{4}{*}{18.67} \\
\hline & 1.3 & 3210 & 2368.6 & 3.31 & \\
\hline & 1.4 & 1760 & 3895.6 & 2.58 & \\
\hline & 1.5 & 765 & 5656.9 & 2.14 & \\
\hline
\end{tabular}




\section{Acknowledgements}

Authors are thankful to UGC, New Delhi, for funding under SAP. The author, K. D. Parikh is thankful to UGC, Pune, for providing the financial assistance under the Minor Research Project. The authors are thankful to Prof. H. H. Joshi (Physics Department, Saurashtra University, Rajkot, India) and Dr. S. U. Vora, (Principal, M. P. Shah Arts \& Science College, Surendranagar) for their keen interest.

\section{REFERENCES}

[1] J. J. De Yoreo, A. K. Burnham and P. K. Whiteman, "Developing $\mathrm{KH}_{2} \mathrm{PO}_{4}$ and $\mathrm{KD}_{2} \mathrm{PO}_{4}$ Crystals for the World's Most Powerful Laser," International Materials Reviews, Vol. 47, No. 3, 2002, pp. 113-152. doi: $10.1179 / 095066001225001085$

[2] R. S. Adhav, "Application of Non Linear Crystal, LIA Hand Book of Laser Materials Processing," Magnolia, 2001.

[3] K. D. Parikh, D. J. Dave, B. B. Parekh and M. J. Joshi, "Thermal, FT-IR and SHG Efficiency Studies of L-Arginine Doped KDP Crystals," Bulletin of Materials Science, Vol. 30, No. 2, 2007, pp. 105-112. doi:10.1007/s12034-007-0019-4

[4] K. D. Parikh, D. J. Dave and M. J. Joshi, "Crystal Growth, Thermal, Optical, and Dielectric Properties of L-Lysine Doped KDP Crystals," Modern Physics Letters B, Vol. 23, No. 12, 2009, pp. 1589-1602. doi:10.1142/S0217984909019740

[5] K. D. Parikh, D. J. Dave, B. B Parekh and M. J. Joshi, "Growth and Characterization of L-Alanine Doped KDP Crystals," Crystal Research and Technology, Vol. 45, No. 6, 2010, pp. 603-610. doi:10.1002/crat.201000019

[6] O. Sohnel, "Electrolyte Crystal-Aqueous Solution Interfacial Tensions from Crystallization Data," Journal of Crystal Growth, Vol. 57, No.1, 1982, pp. 101-108. doi:10.1016/0022-0248(82)90254-8

[7] O. Sohnel and J. W. Mullin, "A Method for the Determination of Precipitation Induction Periods," Journal of Crystal Growth, Vol. 44, No. 4, 1978, pp. 377-382. doi:10.1016/0022-0248(78)90002-7
[8] A. E. Nielson and O. Sohnel“, Interfacial Tensions Electrolyte Crystal-Aqueous Solution from Nucleation Data," Journal of Crystal Growth, Vol. 11, No. 3, 1971, pp. 233242. doi:10.1016/0022-0248(71)90090-X

[9] W. Mullin, "Crystallization," 2nd Edition, Butterworths, London, 1972.

[10] M. S. Joshi and A. V. Antony, "Nucleation in Supersaturated Potassium Dihydrogen Orthophosphate Solutions," Journal of Crystal Growth, Vol. 46, No. 1, 1979, pp. 7-9. doi:10.1016/0022-0248(79)90100-3

[11] B. K. Paul and M. S. Joshi, "The Effect of Supersaturation on the Induction Period of Potassium Dihydrogen Phosphate Crystals Grown from Aqueous Solution," Journal of Physics D: Applied Physics, Vol. 9, No. 1, 1976, pp. 1253-1256. doi:10.1088/0022-3727/9/8/011

[12] M. Shanmugham, F. D. Gnanam and P. Ramasamy, "Nucleation Studies in Supersaturated Potassium Dihydrogen Orthophosphate Solution and the Effect of Soluble Impurities," Journal of Materials Science, Vol. 19, Vol. 9, 1984, pp. 2837-2844. doi:10.1007/BF01026958

[13] M. Shanmugham, F. D. Gnanam and P. Ramasamy, "Non-Steady State Nucleation Process in KDP Solutions in the Presence of $\mathrm{XO}_{4}$ Impurities," Journal of Materials Science Letters, Vol. 4, Vol. 6, 1985, pp. 746-749. doi:10.1007/BF00726978

[14] C. Mahadevan, G. Janiland Angel, U. Anton Sophana and V. Unayorubhagan, "Nucleation Studies in Supersaturated Aqueous Solutions of $\mathrm{KH}_{2} \mathrm{PO}_{4}$ Doped with $\mathrm{KBr}$ and $\mathrm{K}_{2} \mathrm{Cr}_{2} \mathrm{O}_{7}$," Bulletin of Materials Science, Vol. 22, No. 4, 1999, pp. 817-820. doi:10.1007/BF02745612

[15] P. V. Dhanaraj, K. S. Mathew and N. P. Rajesh, "Nucleation Studies and Characterization of Potassium Dihydrogen Phosphate Single Crystals with L-arginine Monohydrochloride as Aadditive," Journal of Crystal Growth, Vol. 310, No. 10, 2008, pp. 2532-2536. doi:10.1016/j.jcrysgro.2007.12.001

[16] P. A. Barata and M. L. Serrano, "Salting-Out Precipitation of Potassium Dihydrogen Phosphate (KDP) II. Influence of Agitation Intensity," Journal of Crystal Growth, Vol. 163, No. 4, 1996, pp. 426-433. doi:10.1016/0022-0248(95)00987-6

[17] A. C. Zettlemoyer, "Nucleation," Marcel Dekker, New York, 1969. 